\title{
INCLUSÃO EXCLUDENTE: PARA UMA ANÁLISE CRÍTICA DA POLÍTICA PÚBLICA DE INCLUSÃO DOS ALUNOS COM NECESSIDADES ESPECÍFICAS NAS ESCOLAS PÚBLICAS
}

\author{
Priscila Tinelli Pinheiro* \\ Rafael Fávero Farias** \\ Alexandre de Castro Coura***
}

SUMÁRIO: Introdução; 2 A educação como direito social fundamental; 3 Análise da teoria do reconbecimento de Charles Taylor; 4 Tentativa de superação da exclusão de alunos com necessidades específicas à luz da teoria de Taylor; 5 Considerações finais; Referências.

RESUMO: Este estudo teve como objetivo analisar a possibilidade de as políticas públicas intencionadas à inclusão acarretarem exclusão de alunos com necessidades específicas que ingressaram na rede regular de ensino a partir da análise da situação no município de Vitória - ES. Tal ingresso se deu a partir da determinação da Lei de Diretrizes e Bases da Educação Nacional (LDBN no 9394/2004) para que a educação especial fosse fornecida preferencialmente nas escolas regulares. Com base na análise dos dados fornecidos pela Secretaria de Municipal de Educação referente à quantidade de escolas da rede pública de ensino classificadas como acessíveis, investiga-se o modo pelo qual se dá esta inclusão das pessoas com necessidades específicas no âmbito educacional. Como resultado, destacou-se a insuficiência de uma política limitada ao mero ingresso de grupo minoritário em determinados ambientes, do ponto de vista de uma efetiva inclusão.

PALAVRAS-CHAVE: Direito à educação; Acessibilidade; Políticas públicas; Reconhecimento; Charles Taylor.

\section{EXCLUDING INCLUSION: FOR A CRITICAL ANALYSIS OF THE PUBLIC POLICY OF INCLUSION OF STUDENTS WITH SPECIAL NEEDS IN PUBLIC SCHOOLS}

ABSTRACT: This study aimed to analyze the possibility of public policies intended to inclusion would entail the exclusion of students with special needs enrolled in

\footnotetext{
Advogada. Doutoranda e Mestre em Direitos e Garantias Constitucionais pela Faculdade de Direito de Vitória (FDV), Brasil. E-mail: priscilatinelli@hotmail.com

** Assessor jurídico do Ministério Público Federal. Mestre em Direitos e Garantias Constitucionais pela Faculdade de Direito de Vitória (FDV), Brasil.

${ }^{* * * *}$ Promotor de Justiça Cível da Comarca da Serra/ES. Pós-doutorado como visiting scholar na American University e visiting foreign judicial fellow no Centro Judiciário Federal em Washington D.C. Docente no Programa de Mestrado e Doutorado da Faculdade de Direito de Vitória (FDV), Brasil.
} 
the regular school system from the analysis of the situation in Vitória, capital of Espírito Santo. This input is given from the determination of the Law of Guidelines and Bases of National Education (LDBN n $\left.{ }^{\circ} 9394 / 2004\right)$ so that special education be provided preferably in regular schools. Based on the analysis of the data provided by the Municipal Department of Education regarding the number of schools in the public school system classified as accessible, it is investigated the way in which this inclusion of people with special needs in the educational scope occurs. As a result, the highlight was the failure of a policy limited to the mere entry of minority group in certain environments, from the point of view of effective inclusion.

KEY WORDS: Right to education; Accessibility; Public Policy; Recognition; Charles Taylor.

\section{INCLUSIÓN EXCLUIDA: PARA UN ANÁLISIS CRÍTICA DE LA POLÍTICA PÚBLICA DE INCLUSIÓN DE LOS ALUMNOS CON NECESIDADES ESPECÍFICAS EN LAS ESCUELAS PÚBLICAS}

RESUMEN: Este estudio para analizar la posibilidad de publicar políticas destinadas a incluir la exclusión de los estudiantes con necesidades especiales enrolladas en el sistema escolar regular del análisis de la situación en Victoria, capital de Espírito Santo. Este ingreso se deduce de la determinación de la Ley de Directrices y Bases de la Educación Nacional (LDBN no 9394/2004) para que se incluya una educación especial en las escuelas regulares. Basado en el análisis de la fecha proporcionada por el Departamento de Educación de la comunidad en relación con el número de escuelas en el sistema escolar de la escuela pública establecida, se ha investigado la forma en que se incluye la inclusión de la inclusión de personas con necesidades especiales en el ámbito de aprendizaje. En el caso de que se trate de una propuesta de la Comisión Europea,

PALABRAS CLAVES: Derecho a la educación; Accesibilidad; Políticas úblicas; Reconocimiento; Charles Taylor.

\section{INTRODUÇÃO}

A educação é um direito de todos e, ao mesmo tempo, um dever do Estado e da família, o qual se encontra previsto na Constituição Federal de 1988 no rol dos direitos sociais. O seu acesso deve, em virtude disto, ser garantido a todos os cidadãos brasileiros de forma igualitária. 
Nesta medida, o Estado é responsável pelo estabelecimento de condições que viabilizem este acesso à educação, principalmente, por aqueles que possuem alguma restrição, como as pessoas com necessidades específicas - que constituem o objeto de análise do presente estudo.

Desta forma, o presente artigo tem por objetivo analisar a possibilidade destas políticas públicas, implementadas pelo Estado, a fim de possibilitar a inclusão dos deficientes nas escolas da rede regular de ensino, acarretarem, ao invés disto, uma situação de exclusão destes alunos. O que, por sua vez, pode ocorrer em face de um reconhecimento errôneo ou um não reconhecimento.

A fim de investigar este possível reconhecimento errôneo diante da realidade social encontrada no ambiente escolar, utilizar-se-á a teoria de Charles Taylor como forma de verificar se o simples ingresso destes alunos com necessidades específicas é suficiente para incluí-los na escola com a preservação de sua identidade.

Para tanto, num primeiro momento, abordar-se-á a educação como um direito social fundamental que deve estar disponível a todos mediante as ações estatais, bem como se analisarão as medidas já adotadas pelo município de Vitória/ ES para a inclusão de alunos com necessidades específicas nas escolas da rede regular de ensino.

Em um segundo momento, será discutida a teoria de Charles Taylor no que tange à política do reconhecimento na qual o autor se debruça em uma tentativa de definir até onde e como o reconhecimento faz parte do modelamento de identidades individuais e coletivas, lançando-se as bases para o enfrentamento do problema em questão. Busca-se, neste sentido, verificar, por meio do estudo dos dados fornecidos pela Secretaria de Municipal de Educação referente à quantidade de escolas da rede pública de ensino classificadas como acessíveis, a maneira pela qual ocorre a inclusão das pessoas com necessidades específicas nestes espaços.

Por último, investigar-se-á a possibilidade de as políticas públicas de inclusão que geram exclusão superarem tal cenário, partindo do pressuposto de que o reconhecimento somente é estabelecido com o respeito e a preservação da identidade das minorias.

\section{A EDUCAÇÃO COMO DIREITO SOCIAL FUNDAMENTAL}

A Constituição Federal de 1988 representou um marco com relação à regulamentação de variadas questões e, no que tange à matéria educacional, não foi 
diferente, tendo em vista a sua consagração de forma efetiva como um direito social fundamental ao ser incorporada ao artigo $6^{\circ}$ da CFRB.

Acerca do status fundamental conferido ao direito à educação, Barretto ${ }^{04}$ aduz que

[...] dentro de uma interpretação ética dos direitos humanos, fundada em valores intrínsecos à racionalidade humana, devem-se compreender os direitos sociais como direitos essenciais e inafastáveis, por conseguinte fundamentais. A partir dessa eticidade dos direitos humanos, pode-se falar em direitos fundamentais sociais, quais sejam, aqueles que, em vez de serem direitos contra o Estado, se constituem em direitos através do Estado, exigindo do Poder Público certas prestações materiais [...].

Com base no trecho citado e à luz da importância assumida pela educação na formação social, é possível classificá-la como algo além do direito social, uma vez que "[...] ínsita no direito à vida, é instrumento fundamental para que o homem possa se realizar como homem" 05 . Ou seja, constitui-se em uma das bases para o exercício de outros direitos igualmente garantidos em âmbito constitucional.

Neste sentido, a constituinte de 1988 destinou um capítulo para tratar das especificidades que compreende a educação, qual seja o capítulo III do título VIII que se destina ao tema da educação, cultura e desporto. O primeiro dispositivo constitucional desta matéria - artigo 205 - dispõe que "a educação, direito de todos e dever do Estado e da família, será promovida e incentivada com a colaboração da sociedade, visando ao pleno desenvolvimento da pessoa, seu preparo para o exercício da cidadania e sua qualificação para o trabalho" ${ }^{" 06}$.

Extrai-se, a partir da redação deste artigo, a natureza bifronte do conceito apresentado, ou seja, a educação é apresentada, ao mesmo tempo, como um direito e um dever. Desta forma, o primeiro aspecto do conceito nos remete à ideia da educação como um direito de todos, o que significa que todos os brasileiros devem ter acesso à educação.

Já o segundo aspecto traz o conceito da educação como um dever, tanto do Estado quanto da família. Destaca-se, neste sentido, que

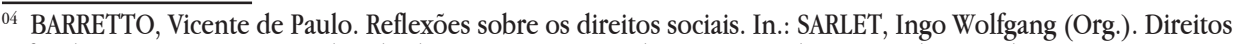
fundamentais sociais: estudos de direito constitucional internacional comparado. Rio de Janeiro: Renovar, 2003. p. 124.

${ }^{05}$ LINHARES, Monica Teresa Mansur. Ensino jurídico: educação, currículo e diretrizes curriculares no curso de Direito. São Paulo: Iglu, 2010. p. 108.

${ }^{06}$ BRASIL. Constituição [da] República Federativa do Brasil. Disponível em: < http://www.planalto.gov.br/ccivil_03/constituicao/ConstituicaoCompilado.htm >. Acesso em: 06 de jan. de 2015.
} 
Perante o direito à educação como direito fundamental ao Estado surge um dever de atuar positivamente, seja i) criando condições normativas adequadas ao exercício desse direito (legislação), seja, ii) na criação de condições reais, com estruturas, instituições e recursos humanos (as chamadas garantias institucionais relacionadas diretamente a direitos fundamentais $)^{07}$.

Com base no trecho supracitado, é possível afirmar que o Estado deverá atuar como garantidor do acesso à educação a todos, ou seja, ele deve criar mecanismos que deem condições a todos os brasileiros de usufruir do ensino regular, o que está expresso no rol do artigo constitucional 208.

É justamente sobre estas condições que devem ser criadas pelo Estado, para que todos tenham acesso à educação que o presente estudo se destina à análise, em especial, o acesso das pessoas com necessidades específicas à rede regular de ensino.

Sobre esta temática, o artigo $4^{\circ}$ da Lei de Diretrizes e Bases da Educação Nacional (lei n. 9394/96), bem como o inciso III do artigo 208 da CFRB/88 prevê, dentre outras garantias, "[...] que o dever do Estado com a educação escolar pública será efetivado mediante: III - atendimento educacional especializado gratuito aos educandos com necessidades especiais, preferencialmente na rede regular de ensino" 08 .

Tal medida representa um avanço - por parte do Poder Estatal - na garantia do acesso à educação às pessoas com necessidades específicas, mas não podemos olvidar das implicações que tal medida contempla, as quais, no cenário da educação brasileira atual, ainda não conseguiram ser efetivadas, tendo em vista a falta de capacitação dos professores e funcionários, bem como a falta de estrutura física para a promoção de tal política pública.

Por outro lado, há o dever da família no cumprimento deste direito à educação -igualmente expresso no artigo $6^{\circ}$ da LBDN - ao dispor que "é dever dos pais ou responsáveis efetuar a matrícula dos menores, a partir dos sete anos de idade, no ensino fundamental". Isto significa que não basta que o Estado forneça a educação - em atendimento aos preceitos constitucionais - se, em contrapartida, os pais não viabilizarem o ingresso de seus filhos nas redes regulares de ensino. Nesta

\footnotetext{
${ }^{07}$ TAVARES, André Ramos. Curso de direito constitucional. 7. ed. São Paulo: Saraiva, 2009. p. 839.

${ }^{08}$ BRASIL. Lei $\mathrm{n}^{\circ}$ 9.394, de 20 de dezembro de 1996. Estabelece as diretrizes e bases da educação nacional. Disponível em: < http://portal.mec.gov.br/seesp/arquivos/pdf/lei9394_ldbn1.pdf>. Acesso em: 09 de jan. de 2015.
} 
medida, tanto a família - pais ou responsáveis pelo menor - quanto o Estado são igualmente responsáveis para a entrada de seus assistidos nestas instituições como forma de efetivação do direito à educação.

Com relação ao tratamento destinado à educação especial, a LDBN, no artigo 58, dispõe acerca de algumas especificidades, dentre as quais se destaca que a oferta desta modalidade educacional ocorrerá preferencialmente na rede regular de ensino. Isso significa que a regra é a criação, pelo Estado, de um ambiente adequado para a oferta do ensino àqueles que possuem algum tipo de deficiência física objeto deste estudo - nas redes regulares de ensino e, somente na falta deste, é que estes indivíduos deverão usufruir da educação em locais especializados.

Neste viés reflexivo, destaca-se que a proteção e o reconhecimento dos direitos dos seres viventes estruturam e fazem emergir a base das Constituições democráticas modernas, sendo que nenhum ser deve ser privado de tal proteção e reconhecimento. O ser humano, pertencente a esse grupo de seres viventes, também não pode ser despojado desses direitos, uma vez que os direitos conquistados pertencem a todos indiscriminadamente.

Na esteira de Bobbio ${ }^{09}$, "os direitos do homem são os que cabem ao homem enquanto homem". Desta forma, as diferenças existentes entre os homens não deve ser óbice para que indivíduos sejam excluídos, devendo todos os homens, de forma indiscriminada, possuir os mesmos direitos, independentemente de suas diferenças.

Partindo do princípio da isonomia, a Constituição da República Federativa do Brasil garante o direito de todos os cidadãos, uma vez que em seu artigo $5^{\circ}$, inciso I, garante a igualdade de todos perante a lei, ao afirmar que

Art. $5^{\circ}$ Todos são iguais perante a lei, sem distinção de qualquer natureza, garantindo-se aos brasileiros e aos estrangeiros residentes no País a inviolabilidade do direito à vida, à liberdade, à igualdade, à segurança e à propriedade, nos termos seguintes:

I - homens e mulheres são iguais em direitos e obrigações, nos termos desta Constituição;10

Também a Declaração Universal dos Direitos do Homem da Organização das Nações Unidas (ONU) assevera essa igualdade, a qual deve ser assegurada e respeitada por todos os Estados que adotaram os seus termos. Para Bobbio ${ }^{11}$,

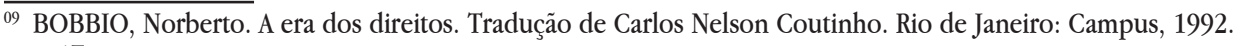
p. 17.

${ }^{10}$ BRASIL. Constituição [da] República Federativa do Brasil. Disponível em: < http://www.planalto.gov.br/ccivil_03/constituicao/ConstituicaoCompilado.htm>. Acesso em: 06 de jan. de 2015.

${ }^{11}$ BOBBBIO, Norberto. A era dos direitos. Tradução de Carlos Nelson Coutinho. Rio de Janeiro: Campus, 1992. p. 5.
} 
A concepção individualista da sociedade procede lentamente, indo do reconhecimento dos direitos do cidadão de cada Estado até o reconhecimento dos direitos do cidadão do mundo, cuja primeiro anúncio foi a Declaração Universal dos Direitos do Homem.

Não podemos descartar os benefícios e os direitos conquistados com a universalização dos direitos humanos, principalmente, após os massacres ocorridos no século passado, mas não podemos fechar os olhos para o fato de que os seres humanos possuem diferenças, seja por meio da renda, etnia, nacionalidade, religião, física ou psicológica, entre outras, sendo que a sociedade e o direito não podem discriminá-las por tais diferenças.

Nesse contexto, faz-se necessária a discussão acerca da efetiva inclusão de pessoas com necessidades específicas em ambientes plurais - como o escolar - o que não se perfaz com a simples ocupação de espaço, mas com o travamento de relações com os demais seres sociais.

A partir, então, do direito fundamental à educação, destacam-se alguns pontos importantes acerca da acessibilidade. Neste sentido, o artigo $3^{\circ} \mathrm{da}$ Constituição da República de 1988, ao traçar os objetivos fundamentais do Estado brasileiro aduz que: "constituem objetivos fundamentais da República Federativa do Brasil: [...] Promover o bem de todos, sem preconceitos de origem, raça, sexo, cor, idade e quaisquer outras formas de discriminação"12.

Extrai-se, com base no texto constitucional supracitado, que o Estado deve garantir e promover o desenvolvimento de condições que assegurem aos participantes do Estado, ou seja, o povo, a isonomia nas atividades por ele realizadas, a fim de afastar qualquer forma de discriminação ou preconceito e conquistar uma sociedade livre, justa e igualitária.

Por seu turno, conforme exposto, a educação é considerada uma das formas de se obter uma igualdade material e tornar a sociedade na qual vivemos livre, justa e igualitária. A Declaração da Salamanca de 1994, considerado mundialmente, um dos mais importantes documentos ao se tratar de inclusão social, reitera o direito e o compromisso com a educação como direito de todos, cabendo ao Estado, por meio das escolas o dever de encontrar maneiras de educar com êxito todos os cidadãos, inclusive aqueles com deficiência.

Negados por sua diferença, as pessoas com necessidades específicas tornaram-se, nos últimos anos, um dos precursores do ideal de igualdade que os seres humanos pretendem conquistar e manter em todos os âmbitos da vida,

${ }_{12}$ BRASIL. Constituição [da] República Federativa do Brasil. Disponível em: < http://www.planalto.gov.br/ccivil_03/constituicao/ConstituicaoCompilado.htm>. Acesso em: 06 de jan. de 2015. 
principalmente, na área educacional. A inclusão destas pessoas no âmbito escolar tem fundamental importância, haja vista que é neste local que se inicia a formulação de conceitos e ideias, sendo primordial a igualdade de ensino a todos.

A Convenção Interamericana para a Eliminação de Todas as Formas de Discriminação contra as Pessoas Portadoras de Deficiência, promulgada pelo decreto $\mathrm{n}^{\mathrm{0}} 3.956$ de 08 de outubro de 2001, ao considerar o Princípio da Igualdade como base de uma sociedade justa, assevera que

Os Estados Partes nesta Convenção, [...] Reafirmando que as pessoas portadoras de deficiência têm os mesmos direitos humanos e liberdades fundamentais que outras pessoas e que estes direitos, inclusive o direito de não ser submetidas a discriminação com base na deficiência, emanam da dignidade e da igualdade que são inerentes a todo ser humano ${ }^{13}$.

Diante da Convenção, cabe ao Estado a garantia de eliminação progressiva da discriminação, bem como o fornecimento de mecanismos que facilitem a locomoção e o acesso dessas pessoas em todo o território nacional, conforme preceitua o artigo $1^{\mathrm{o}} \mathrm{da}$ Convenção citada, o qual salienta que para alcançar tais objetivos os Estados partes comprometem-se a

1. Tomar as medidas de caráter legislativo, social, educacional, trabalhista, ou de qualquer outra natureza, que sejam necessárias para eliminar a discriminação contra as pessoas portadoras de deficiência e proporcionar a sua plena integração à sociedade, entre as quais as medidas abaixo enumeradas, que não devem ser consideradas exclusivas:

a) medidas das autoridades governamentais e/ou entidades privadas para eliminar progressivamente a discriminação e promover a integração na prestação ou fornecimento de bens, serviços, instalações, programas e atividades, tais como o emprego, o transporte, as comunicações, a habitação, o lazer, a educação, o esporte, o acesso à justiça e aos serviços policiais e as atividades políticas e de administração; b) medidas para que os edifícios, os veículos e as instalações que venham a ser construídos ou fabricados em seus respectivos territórios facilitem o transporte, a comunicação e o acesso das pessoas portadoras de deficiência;

c) medidas para eliminar, na medida do possível, os obstáculos arquitetônicos, de transporte e comunicações que existam, com a finalidade de facilitar o acesso e uso por parte das pessoas portadoras de deficiência; e

${ }_{13}$ BRASIL. Decreto n ${ }^{0} 3.956$, de 8 de outubro de 2001. Promulga a Convenção Interamericana para a Eliminação de Todas as Formas de Discriminação contra as Pessoas Portadoras de Deficiência. Disponível em: <http:// www.planalto.gov.br/ccivil_03/decreto/2001/d3956.htm >. Acesso em: 09 de jan. de 2015. 
d) medidas para assegurar que as pessoas encarregadas de aplicar esta Convenção e a legislação interna sobre esta matéria estejam capacitadas a fazê-lo ${ }^{14}$.

Com o intuito de tornar acessíveis os locais públicos e também privados, a Comissão de Edificações e Meio, por meio do Comitê Brasileiro de Acessibilidade, criou a Norma Técnica $\mathrm{n}^{0} 9.050$ de 2004 (ABNT NBR 9050:2004), que traçou critérios, tais como "[...] parâmetros técnicos a serem observados quando do projeto, construção, instalação e adaptação de edificações, mobiliário, espaços e equipamentos urbanos às condições de acessibilidade"15.

De outra banda, conforme já afirmado, a Constituição brasileira garante a educação a todas as crianças e adolescentes, bem como o Estatuto da Criança e do Adolescente reafirma tal direito inclusive às pessoas com necessidades específicas. De acordo com o Estatuto, de 13 de julho de 1990:

Art. 53: A criança e o adolescente têm direito à educação, visando ao pleno desenvolvimento de sua pessoa, preparo para o exercício da cidadania e qualificação para o trabalho, assegurando-se lhes:

I - igualdade de condições para o acesso e permanência na escola;

II - direito de ser respeitado por seus educadores;

III - direito de contestar critérios avaliativos, podendo recorrer às instâncias escolares superiores;

IV - direito de organização e participação em entidades estudantis;

V- acesso à escola pública e gratuita próxima de sua residência;

Art. 54: É dever do Estado assegurar à criança e ao adolescente:

III - atendimento educacional especializado aos portadores de deficiência, preferencialmente na rede regular de ensino; ${ }^{16}$

Conforme garantido pela Lei de Diretrizes e Bases da Educação (lei $\mathrm{n}^{\mathrm{o}}$ 9.394, de 20 de dezembro de 1996), o atendimento educacional especializado deve ocorrer, preferencialmente, na rede regular de ensino, assim lecionado pelo art. 4, III da referida lei: "atendimento educacional especializado gratuito aos educandos

${ }^{14}$ BRASIL. Decreto ${ }^{0} 3.956$, de 8 de outubro de 2001. Promulga a Convenção Interamericana para a Eliminação de Todas as Formas de Discriminação contra as Pessoas Portadoras de Deficiência. Disponível em: <http:// www.planalto.gov.br/ccivil_03/decreto/2001/d3956.htm >. Acesso em: 09 de jan. de 2015.

15 ASSOCIAÇÃO BRASILEIRĀ DE NORMAS TÉCNICAS. NBR no 9050:2004. Disponível em: <http://www. pessoacomdeficiencia.gov.br/app/sites/default/files/arquivos/\%5Bfield_generico_imagens-filefield-description\%5D_24.pdf>. Acesso em: 06 jan. 2015.

${ }^{16}$ BRASIL. Lei no 8.069, de 13 de julho de 1990. Dispõe sobre o Estatuto da Criança e do Adolescente e dá outras providências. Disponível em: < http://www.planalto.gov.br/ccivil_03/eis/18069.htm> . Acesso em: 09 de jan. de 2015. 
com necessidades especiais, preferencialmente na rede regular de ensino"17.

$\mathrm{O}$ artigo $2^{\circ}$, inciso I da lei $\mathrm{n}^{\mathrm{o}} 7.853$ de 1989 , assegura às pessoas com deficiência e incube ao Poder Público

[...] o pleno exercício de seus direitos básicos, inclusive dos direitos à educação [...] Parágrafo único. Para o fim estabelecido no caput deste artigo, os órgãos e entidades da administração direta e indireta devem dispensar, no âmbito de sua competência e finalidade, aos assuntos objetos esta Lei, tratamento prioritário e adequado, tendente a viabilizar, sem prejuízo de outras, as seguintes medidas:

I - na área da educação:

a) a inclusão, no sistema educacional, da Educação Especial como modalidade educativa que abranja a educação precoce, a pré-escolar, as de $1^{\circ}$ e $2^{\circ}$ graus, a supletiva, a habilitação e reabilitação profissionais, com currículos, etapas e exigências de diplomação própria; b) a inserção, no referido sistema educacional, das escolas especiais, privadas e públicas;

c) a oferta, obrigatória e gratuita, da Educação Especial em estabelecimento público de ensino;

d) o oferecimento obrigatório de programas de Educação Especial a nível pré escolar, em unidades hospitalares e congêneres nas quais estejam internados, por prazo igual ou superior a 1 (um) ano, educandos portadores de deficiência;

e) o acesso de alunos portadores de deficiência aos benefícios conferidos aos demais educandos, inclusive material escolar, merenda escolar e bolsas de estudo;

f) a matrícula compulsória em cursos regulares de estabelecimentos públicos e particulares de pessoas portadoras de deficiência capazes de se integrarem no sistema regular de ensino; ${ }^{18}$

Como forma de preservar os princípios acima enunciados, torna-se necessária uma capacitação dos profissionais de educação para os variados tipos de deficiência, bem como uma modificação das edificações e espaços físicos de forma geral e nas escolas especificamente para que se viabilize o acesso a todas as áreas pelos alunos, sejam esses com necessidades específicas ou não.

Escolas que se pretendam inclusivas devem ser acessíveis a todas as pessoas da sociedade, sendo fundamental que a rede de ensino disponha de educadores

$\overline{17}$ BRASIL. Lei $\mathrm{n}^{\circ}$ 9.394, de 20 de dezembro de 1996. Estabelece as diretrizes e bases da educação nacional. Disponível em: < http://portal.mec.gov.br/seesp/arquivos/pdf/lei9394_ldbn1.pdf>. Acesso em: 09 de jan. de 2015.

${ }^{18}$ BRASIL. Lei $n^{0} 7.853$ de 1989. Dispõe sobre o apoio às pessoas portadoras de deficiência, sua integração social, sobre a Coordenadoria Nacional para Integração da Pessoa Portadora de Deficiência - Corde, institui a tutela jurisdicional de interesses coletivos ou difusos dessas pessoas, disciplina a atuação do Ministério Público, define crimes, e dá outras providências. Disponível em: < http://www.planalto.gov.br/ccivil_03/leis/L7853. htm >. Acesso em: 10 jan. de 2015. 
capacitados para lidar com todas as formas de diferenças e desenvolvimento de mecanismos e de políticas de acessibilidade física e de comunicação e, sobretudo, promovam o atendimento educacional especializado, conforme a determinação legal.

O engajamento da escola deve estar no desenvolvimento de uma pedagogia voltada para o aluno, que possibilite educar a todos de forma equânime e com qualidade. Os professores, alicerces deste trabalho, devem encontrar meios para se adequarem a esse novo modelo de educação inclusiva. $\mathrm{O}$ acesso, das pessoas com necessidades específicas, com a construção de espaços e edificações voltadas para essa realidade, também influi de maneira positiva em uma educação de qualidade e equitativa. Nesse linear, Guenther, ${ }^{19}$ ao analisar as diretrizes para uma educação inclusiva, vai além ao afirmar que

A política de inclusão de alunos na rede regular de ensino não consiste somente na permanência física desses alunos junto aos demais educandos, mas representa a ousadia de rever concepções e paradigmas, bem como desenvolver o potencial dessas pessoas, respeitando suas diferenças e atendendo suas necessidades.

O mundo sempre está em constante mudança, assim como o ser humano e a sociedade precisam estar preparados para estas mudanças, pois como nas palavras de Arthur Guimarães ${ }^{20}$ : "a inclusão é um processo cheio de imprevistos sem fórmulas prontas e que exige o aperfeiçoamento constante”. É um processo necessário, mas que deve ser feito com respeito e cuidado, a fim de que as políticas de inclusão não acarretem a exclusão ainda maior.

Após esta reflexão acerca da necessidade da transformação das escolas públicas e a fim de que se tornem acessíveis a todos, analisar-se-á, de forma específica, a situação da rede de ensino do município de Vitória-ES, a qual possui atualmente $102^{21}$ escolas, das quais 49 unidades são denominadas de centros municipais de educação infantil e as demais 53 unidades destinam-se ao ensino fundamental. Destaca-se que, dentre este total de escolas ${ }^{22}$, são consideradas acessíveis 31 escolas municipais de ensino fundamental e 43 centros municipais de educação infantil.

$\overline{19}$ GUENTHER, Zenita Cunha. O aluno bem-dotado na escola regular: celebrando a diversidade, incluindo as diferenças. Revista Escritos sobre Educação, Ibirité, v. 2, n.1, jan-jun. 2003. p. 47.

${ }^{20}$ GUIMARÃES, Arthur. Inclusão que funciona. Revista Nova Escola, São Paulo, n. 165, set. 2003. p. 44.

${ }^{21}$ Optou-se por analisar a totalidade das escolas de ensino fundamental, pois a LDBN, em seu artigo $58, \S 3^{\circ}$, dispõe que "a oferta de educação especial [...] tem início na faixa etária de zero a seis anos, durante a educação infantil".

${ }^{22}$ Os dados apresentados foram informados pela Secretaria Municipal de Educação, por meio do ofício $\mathrm{n}^{\circ}$ 077/2012/SEME/GAB na data de 26 de janeiro de 2015, em atendimento ao protocolo PMV nº 97/2015. 
De outra banda, sete escolas de ensino fundamental são consideradas parcialmente acessíveis, 13 escolas de ensino fundamental e cinco centros de educação infantil não possuem acessibilidade.

A partir dos dados apresentados, pode-se observar que há a tendência, por parte dos órgãos responsáveis pela educação, em tornarem as unidades escolares mais acessíveis aos seus alunos. Isso significa que é possível identificar maior quantidade de alunos com necessidades específicas frequentando as escolas, contudo investigaremos - a partir daqui - se esta inclusão realizada, ao menos, de maneira formal é capaz de promover o reconhecimento, com base na teoria de Charles Taylor, destes indivíduos perante a sociedade onde estão inseridos.

\section{ANÁLISE DA TEORIA DO RECONHECIMENTO DE CHARLES TAYLOR}

De início podemos destacar que Charles Taylor se debruça na tentativa de definir até onde e como o reconhecimento faz parte do modelamento de identidades individuais e coletivas. De acordo o filósofo canadense, o reconhecimento tornase de suma importância no cenário atual, uma vez que - em sua perspectiva mais importante - entrecruza-se com a construção das identidades dos indivíduos que compõem a sociedade.

Por meio do reconhecimento proposto por Taylor é possível vislumbrar em cada indivíduo - uma "voz interior" que é só sua e que deve ser ouvida, sendo esta voz que nos faz acreditar pertencer, ou não, a uma determinada sociedade.

Sem o reconhecimento, nossa identidade não estaria totalmente preenchida, haja vista que é a identidade que permite a cada pessoa perceber "como é que a suas características fundamentais fazem dela um ser humano" ${ }^{\prime 2}$. De acordo com o filósofo,

a tese consiste no facto de a nossa identidade ser formada, em parte, pela existência ou inexistência de reconhecimento e, muitas vezes, pelo reconhecimento incorrecto dos outros, podendo uma pessoa ou grupo de pessoas serem realmente prejudicadas, serem alvo de verdadeira distorção, se aqueles que os rodeiam reflectirem uma imagem limitativa, de inferioridade ou de desprezo por eles mesmos. O não reconhecimento ou reconhecimento incorrecto podem afectar negativamente, podem ser uma forma de agressão, reduzindo a pessoa a uma maneira de ser falsa, distorcida, que a restringe ${ }^{24}$.

$\overline{23}$ TAYLOR, Charles. Argumentos filosóficos. Tradução de Adail Ubirajara Sobral. São Paulo: Loyola, 1998. p. 45.

${ }^{24}$ Ibidem, 1998. p. 45. 
Os seres humanos passam a se constituir e a se reconhecer pelo reconhecimento (correto ou incorreto). A realização do reconhecimento em sua forma negativa pode gerar perturbação sem precedentes na maneira como os indivíduos conduzem suas vidas. Além disso, colocando-os na condição de seres inferiores, subjugados, oprimidos e despido de dignidade e liberdade, em comparação a outros grupos sociais.

Para Taylor, a realização do reconhecimento incorreto pode acarretar não só uma ausência de respeito que é devido a todos, mas "também marcar as suas vítimas de forma cruel, subjugando-as através de um sentimento incapacitante de ódio contra elas mesmas. Por isso, o respeito devido não é um acto de gentileza para com os outros. É uma necessidade humana vital" 25 .

Nessa esteira, verifica-se que a política de reconhecimento proposta por Taylor está no cerne da sociabilidade humana. A concepção de reconhecimento se manifesta em dois âmbitos: primeiro, no plano íntimo e, segundo, no plano social. O reconhecimento no plano íntimo caracteriza-se como aquele em que é construída a identidade individual é, ainda, o momento em que o indivíduo conhece a si mesmo. Por sua vez, o plano social, é onde se constrói uma política de reconhecimento. Seguindo a cátedra de Appiah" ${ }^{26}$

a ligação entre a identidade individual, por um lado, que é o centro da discussão de Taylor, e estas identidades coletivas, por outro lado, parece ser algo como isto: a identidade individual de cada pessoa é vista como tendo duas dimensões principais. Há uma dimensão colectiva, a intersecção das suas identidades colectivas, e há uma dimensão pessoal, que consiste em características social ou moralmente importantes - inteligência, charme, perspicácia, cobiça - que não são elas próprias as bases das formas de identidade colectiva.

Parece-nos que a ideia defendida por Charles Taylor é a de que o caminho que percorremos em nossas vidas deve fazer algum sentido, sendo que tais caminhos nos são fornecidos por estas identidades coletivas. Neste sentido, Appiah ${ }^{27}$ leciona que "transculturalmente importa às pessoas que as suas vidas tenham uma

\footnotetext{
${ }_{25}$ TAYLOR, Charles. Argumentos filosóficos. Tradução de Adail Ubirajara Sobral. São Paulo: Loyola, 1998. p. 46. ${ }^{26}$ APPIAH, K. Anthony. Identidade, Autenticidade, Sobrevivência: sociedades multiculturais e reprodução social. In: TAYLOR, Charles; et al. Multiculturalismo: examinando a política de reconhecimento. Tradução de Marta Machado. Lisboa: Piaget, 1998, p. 167.

${ }^{27}$ APPIAH, K. Anthony. Identidade, Autenticidade, Sobrevivência: sociedades multiculturais e reprodução social. In: TAYLOR, Charles; et al. Multiculturalismo: examinando a política de reconhecimento. Tradução de Marta Machado. Lisboa: Piaget, 1998, p. 176.
} 
determinada unidade narrativa; querem ser capazes de contar a história das suas vidas que faça sentido". Assim, as identidades constroem-se mediante um processo dialógico e intersubjetivo, em que cada indivíduo apresenta-se e interage no meio social do qual é membro.

A fim de que o ser humano reconheça sua identidade, necessário se faz uma política que lhe conceda espaço para sentar-se à mesa e dialogar publicamente sobre as ideias que podem ser compartilhadas com outros cidadãos. Ausente essa perspectiva, compromete-se qualquer tentativa de socialização em longo prazo, uma vez que os efeitos desse compartilhamento de ideias, em muitos casos, não poderão ser notados em curto espaço de tempo. Nesse linear, afirma Appiah ${ }^{28}$ que o ocidente vivencia, paulatinamente, um ambiente multicultural.

vivemos em sociedades nas quais certos indivíduos não têm sido tratados com igual dignidade porque eram, por exemplo, mulheres, homossexuais, negros, católicos. Como Taylor defende tão persuasivamente, porque as nossas identidades estão dialogicamente moldadas, as pessoas que têm estas características acham-nas centrais - muitas vezes negativamente - para as suas identidades. Hoje em dia, há a concordância bastante difundida que os insultos às suas dignidades e as limitações da sua autonomia impostas em nome destas identidades colectivas estão seriamente errados. Uma forma de curar o eu que os que têm estas identidades compartilham é aprender a ver estas identidades colectivas não como fontes de limitação e insulto mas como uma parte valiosa do que elas centralmente são.

Diante disso, a política de reconhecimento apresenta-se como condição primordial para a construção e manutenção de sociedades democráticas, livres e que têm como basilar o respeito mútuo. Pode-se afirmar que dignidade, respeito e reconhecimento estão entrelaçados na construção de uma vida pautada na ética que tem como objetivo a constituição de seres humanos livres e capazes de enxergar o outro sem as distorções, inferioridades e injustiças praticadas por seu semelhante.

Rockefeller ${ }^{29}$, ao discutir a política de reconhecimento de Taylor, afirma que

O apelo ao reconhecimento do valor igual das diferentes culturas é a expressão da básica e profunda necessidade humana da aceitação incondicional. Um sentimento por tal aceitação, incluindo a confir-

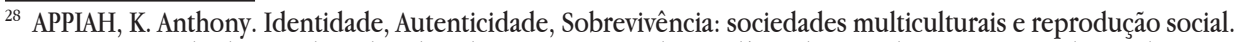
In: TAYLOR, Charles; et al. Multiculturalismo: examinando a política de reconhecimento. Tradução de Marta Machado. Lisboa: Piaget, 1998, p. 176-177.

${ }^{29}$ ROCKEFELLER, Steven C. Comentário. In: TAYLOR, Charles; et al. Multiculturalismo: examinando a política de reconhecimento (Trad. Marta Machado). Lisboa: Piaget, 1998, p. 114.
} 
mação da nossa particularidade étnica e do nosso potencial universalmente partilhado, é uma parte essencial de um forte sentido de identidade. Como Taylor salienta, a formação da identidade de uma pessoa está estritamente ligada a um reconhecimento social positivo - aceitação e respeito - dos pais, amigos e entes queridos, e também de toda a sociedade.

Pelo exposto, a ação dialógica proporciona a construção e reconhecimento das identidades individuais e coletivas podendo ser exercida nos dois âmbitos anteriormente mencionados, íntimo, por meio da relação do indivíduo consigo mesmo, e, social, atuando publicamente e se valendo da política de reconhecimento igualitário a fim de gerar uma identidade social.

No que se refere às pessoas com necessidades específicas em âmbito escolar, essa construção e reconhecimento das identidades se entrelaçam, o íntimo se confunde com o social e vice-versa. Partimos do uno para o múltiplo, para o ser que está no mundo de forma coletiva, mas que necessita de sua individualidade de sua característica primária, de uma identidade que é sua. É neste equilíbrio que Taylor tenta se debruçar.

A partir desse basilar, Taylor faz uma análise sobre o sentido encampado pela política do reconhecimento, sendo que podemos entendê-la por meio de duas formas diversas: a política da igual dignidade e a política da diferença. Dois movimentos que se encontram em constante tensão.

Taylor parte da ideia de uma sociedade que vive em um Estado democrático de Direito de fundamentação liberal, cuja perspectiva é a de igual dignidade para todos os cidadãos (política de igual dignidade). Tal política tem como um de seus grandes estudiosos e defensores o filósofo alemão Jürgen Habermas.

Habermas $^{30}$ sustenta que a política de reconhecimento não necessita e, segundo ele, não caberia qualquer exigência de proteção de maneiras singulares de vida, mas defende a construção de uma esfera pública, uma espécie de ágora grega, onde as diversas singularidades de vida podem expor livremente seus argumentos e os demais indivíduos podem aderir ou não as diferentes formas identitárias.

O filósofo alemão aduz que, em seu entender, a ordem jurídica moderna tem como base direitos individuais, subjetivos, em que as constituições devem ser compreendidas como um arcabouço histórico a ser aperfeiçoado por cada geração.

\footnotetext{
${ }^{30}$ HABERMAS, Jurgen. A Luta por reconhecimento no Estado Democrático de Direito. In: A inclusão do outro estudos de teoria política. Trad. George Sperber e Paulo Astor Soethe. São Paulo: Edições Loyola, capítulo 8, p. 229-254.
} 
Mas de que maneira haverá este cumprimento? Isto dependerá da maneira como os argumentos serão levados à esfera pública, ocasião em que serão debatidas as novas realidades sociais. Para Habermas ${ }^{31}$, ainda que nos casos em que há uma reinterpretação da ordem jurídica acolham-se bens entendidos como coletivos, a distribuição ou a fruição desses bens seria individualizada, mantendo incólume o sustentáculo desta forma de organização social, que se funda em direitos subjetivos individualizados.

Entretanto, não é esse o ponto em que queremos nos aprofundar. Apoiamonos na teoria oposta, que vimos conduzindo durante este artigo e que descreveremos abaixo. Taylor, com base na concepção moderna de identidade apresenta uma forma de política em que o que se demanda não é o universalismo da igualdade entre todos os cidadãos, mas que todos sejam reconhecidos pelas suas identidades singulares, ou seja, "exige-se o reconhecimento da identidade única deste ou daquele indivíduo ou grupo, do caráter singular de cada um"32.

A política da diferença não deixa de adotar uma vertente universalista, entretanto, diversamente da política da igual dignidade - a qual almeja uma universalização dos direitos e garantias para todos os indivíduos - a política da diferença baseia-se num reconhecimento universal da identidade ímpar de cada indivíduo ou de um grupo que é diverso dos demais. No mais, a política da diferença vem delatar e combater as discriminações realizadas pela política da dignidade universal, haja vista que para esta, torna-se complexo demais incorporar a demanda das diferenças e singularidades, já que o que se exige é que a "identidade" seja reconhecida, que não é universalmente compartilhada.

Cabe salientar, que com o surgimento e a percepção da política da diferença, o que se constata é que essa identidade particular no decorrer do tempo, "ignorada, disfarçada, assimilada a uma identidade dominante ou de maioria"33, possui a sua razão de existência. O hiato causado pela inexistência do reconhecimento pelas diferenças extermina qualquer probabilidade da existência do reconhecimento pelas peculiaridades únicas de cada ser humano.

Todavia, pode parecer - à primeira vista - que as políticas aqui descritas são incompatíveis, mas em uma análise mais aprofundada percebe-se que elas são complementares, como afirma o filósofo canadense,

\footnotetext{
${ }^{31}$ HABERMAS, Jurgen. A Luta por reconhecimento no Estado Democrático de Direito. In: A inclusão do outro estudos de teoria política. Trad. George Sperber e Paulo Astor Soethe. São Paulo: Edições Loyola, capítulo 8, p. 229-254.

32 TAYLOR, Charles. Argumentos filosóficos. Tradução de Adail Ubirajara Sobral. São Paulo: Loyola, 1998. p. 58.

33 Ibidem, 1998. p. 58.
} 
o que subjaz à exigência de reconhecimento é um princípio da igualdade universal. A política da diferença implica inúmeras denúncias de discriminação e recusa da cidadania de segunda categoria. É aqui que o princípio de igualdade universal coincide com a política de dignidade. Todavia, as exigências daquela dificilmente são assimiladas nesta, pois tal implica que reconheçamos a importância e o estatuto de algo que não é universalmente comum. Ou, dito de outra maneira, só reconhecemos aquilo que existe universalmente - todos possuem uma identidade -, aquilo que é peculiar a cada um. A exigência universal estimula um reconhecimento da especificidade ${ }^{34}$.

Desta forma, o marco inicial da política da diferença deriva justamente da política da dignidade, uma vez que as duas reivindicam pelo princípio da não discriminação, mesmo que a política da dignidade universal seja cega à maneira como os cidadãos se diferenciam.

Assim, a partir das distinções existentes entre os indivíduos, a política da diferença atribui a não discriminação como exigência de um tratamento diferenciado. Para Taylor ${ }^{35}$ "a exigência adicional que examinamos aqui é que todos reconheçamos o igual valor de diferentes culturas; que não apenas as deixemos sobreviver, mas reconheçamos seu valor". Portanto, não basta que haja um tratamento diferenciado, se este não coexistir com a manutenção do valor de determinado grupo.

\section{TENTATIVA DE SUPERAÇÃO DA EXCLUSÃO DE ALUNOS COM NECESSIDADES ESPECÍFICAS À LUZ DA TEORIA DE TAYLOR}

A partir dos argumentos alhures expostos, pode-se afirmar que há muito a se debater acerca da efetivação de uma política do reconhecimento em relação aos estudantes com necessidades específicas, uma vez que o tratamento que lhes é proporcionado - garantia de acesso previsto no art. 58 da LDB - não é sinônimo de respeito à identidade que lhes é devida.

Nesta esteira, Mattos ${ }^{36}$ afirma que "os dilemas do reconhecimento de diferenças colocam uma série de desafios constitucionais, políticos e sociais”, o que reforça um descompasso entre o ordenamento jurídico e a realidade social e impede, ao mesmo tempo, a completude da teoria do reconhecimento.

\footnotetext{
${ }^{34}$ TAYLOR, Charles. Argumentos filosóficos. Tradução de Adail Ubirajara Sobral. São Paulo: Loyola, 1998. p. 59.

35 TAYLOR, Charles. Argumentos filosóficos. Tradução de Adail Ubirajara Sobral. São Paulo: Loyola, 2000. p. 268.

${ }^{36}$ MATTOS, Patrícia. A sociologia política do reconhecimento: as contribuições de Charles Taylor, Axel Honneth e Nancy Fraser. São Paulo: Annablume, 2006. p. 102.
} 
Existe uma lei que garante o acesso do estudante, desde o ensino primário, à escola. Porém, a partir dos dados obtidos junto à Secretaria da Educação do Município de Vitória/ES, constatam-se que, aproximadamente, 73\% destas escolas não são consideradas acessíveis àqueles que possuem alguma deficiência física.

Diante desta situação, muitos estudantes não possuem escolha a não ser matricularem-se em escolas de outros bairros ou mesmo deixarem de frequentar o ensino regular.

Outro ponto a ser analisado é que estes estudantes ao recorrerem a escolas de outro bairro diferente do seu, eles quebram os laços afetivos, culturais e terão que enfrentar a barreira do desconhecido neste novo ambiente escolar, o que acarreta a perda parcial de sua identidade, uma vez que há influência cultural de seu grupo em sua formação. Existem, por outro lado, aqueles estudantes que não têm condições de procurar escolas em outro bairro pelas mais diversas condições, sejam elas socioeconômicas, políticas e de locomoção.

No que tange às escolas que são consideradas acessíveis, destaca-se que para que a teoria de Taylor seja efetivada - não é suficiente que seja garantido ao indivíduo com deficiência o simples ingresso na unidade escolar, mas, sobretudo, que este ingresso seja possibilitado com o respectivo reconhecimento por parte daquela comunidade. Tal reconhecimento será pleno, portanto, na medida em que houver o devido respeito a este indivíduo e, por conseguinte, as suas limitações.

Nesta perspectiva de que o reconhecimento deve estar atrelado ao devido respeito às diferenças, Taylor ${ }^{37}$ apresenta-nos que

[...] o que é destacado como de valor aqui é um potencial humano universal, uma capacidade de que partilham todos os seres humanos. É nesse potencial, em vez de qualquer coisa que uma pessoa possa ter feito dele, que assegura que cada pessoa merece respeito. De fato, nosso sentido da importância da potencialidade vai tão longe que estendemos essa proteção mesmo a pessoas que, devido a alguma circunstância que as atingiu, são incapazes de realizar seu potencial da maneira normal - por exemplo, deficiente [...].

Em outras palavras, essa potencialidade universal nos leva ao sentido de proteção, o que significa afirmar que a escola deve mudar, mas não de maneira radical. Deve, desta forma, permitir a inclusão deste aluno junto ao grupo sem que ele perca a sua própria identidade. Isto é, que ele participe das atividades educativas e

\footnotetext{
${ }_{37}$ TAYLOR, Charles. Argumentos filosóficos. Tradução de Adail Ubirajara Sobral. São Paulo: Loyola, 2000. p. 253.
} 
aprenda os conteúdos da mesma forma que os demais, desde que haja possibilidades para tanto, as quais ficarão a cargo da construção de uma estrutura adequada - que inclui o aspecto arquitetônico e a contratação de profissionais especializados.

De acordo com a teoria construída por Taylor, deve haver uma maneira de “[...] conciliação entre as demandas de minorias por reconhecimento e o respeito pelos direitos individuais, que estão na base da concepção moderna de individualismo" ${ }^{\text {" }}$. Com relação ao caso do reconhecimento de pessoas com necessidades específicas no ambiente escolar, não se defende, no presente estudo, a transformação da escola de ensino regular em uma unidade para a educação especial, mas - de certa forma adequá-la para o recebimento destes alunos com o objetivo de educá-los conforme suas especificidades. Tal situação seria uma alternativa à preservação dos direitos individuais e o atendimento às demandas da minoria.

A política pública - no caso de inclusão das pessoas com necessidades específicas - constitui-se apenas num primeiro passo, por parte do Estado, a fim de modificar o cenário atual de completa exclusão destas pessoas. Assim, contribuir para o acesso destes alunos à educação, não representa - por completo o reconhecimento - tendo em vista que para a efetivação deste é necessária a presença de um conjunto de fatores, tais como o respeito e a inclusão, o que somente ocorrerá à medida que o grupo receptor da minoria mude de comportamento em prol desta aceitação. Portanto, o reconhecimento, com base na teoria tayloriana não é "[...] uma mera cortesia que devemos conceber às pessoas, mas sim uma necessidade humana vital"39.

Destaca-se que o objeto em análise - acessibilidade nas escolas de Vitória/ES - conta uma política pública, promovida pelo município, intitulada "Programa Escola Acessível”, cuja informação foi obtida junto à Secretaria Municipal de Educação. O referido programa "tem como objetivo promover condições de acessibilidade ao ambiente físico, aos recursos didáticos e pedagógicos, bem como à comunicação e informação nas escolas públicas de ensino regular". Contudo, este é apenas um passo para se atingir um reconhecimento substancial, pois há mais a se fazer e há se compreender, uma vez que

[...] as políticas de ações afirmativas que têm sido implementadas

\footnotetext{
${ }^{38}$ MATTOS, Patrícia. A sociologia política do reconhecimento: as contribuições de Charles Taylor, Axel Honneth e Nancy Fraser. São Paulo: Annablume, 2006. p. 108.

${ }^{39}$ Ibidem, 2006. p. 126.
} 
nos últimos tempos não tocam no aspecto central da discriminação - a necessidade de reconhecimento do igual valor de diferentes culturas, etnias e gênero. Elas acabam gerando um processo apenas de redistribuição de renda, separando, assim, as esferas da economia e da cultura. O problema desse tipo de política é que se imagina que depois de terem sido reparadas as injustiças historicamente desenvolvidas, cessa-se a necessidade de qualquer reconhecimento é que ele é fundamental para o desenvolvimento de nossa identidade, portanto, não possui um prazo de vigência, devendo estar sempre tendo garantias das condições para o exercício indefinido de sua particularidade ${ }^{40}$.

Neste sentido, o reconhecimento constitui-se em um processo paulatino: cabe ao Estado iniciá-lo, por meio da criação de políticas públicas; cabe à sociedade comportar-se de maneira respeitosa e inclusiva; cabe à Constituição a manutenção dos direitos individuais e dos coletivos, mas também a preservação da identidade dos grupos minoritários. Isso significa que o reconhecimento não atingirá seu objetivo somente por meio de ações estatais, mas por um conjunto de atitudes de todos aqueles que se encontram envolvidos neste processo permanente.

É certo que harmonizar estes objetivos apresenta-se, em muitos casos, inconciliável em uma sociedade que se mostra individualizada e liberal. Todavia, há caminhos dentro de um Estado Liberal e individualista de se pautar a política do reconhecimento em atos de respeito, tomando como base, por exemplo, estudos realizados sobre o valor desses grupos, uma vez que, muitas vezes, não se consegue enxergar as contribuições que esses grupos podem dar a sociedade, por serem diferentes daquilo que nossa visão consegue alcançar.

Como alternativas de inclusão, no âmbito escolar, podem-se enumerar ações como seminários, atividades integrativas dos alunos e trabalhos que envolvam tanto o corpo docente, quanto o discente, a fim de colocar os alunos com necessidades específicas como protagonistas destas ações, com o objetivo de torná-los - de maneira efetiva - parte integrante daquele espaço.

O programa mencionado nesta pesquisa, ao qual o município de Vitória/ES fez aderência, bem como as escolas e unidade de educação que possuem total ou parcial acessibilidade, são um passo importante para se atingir um reconhecimento substancial, mas sem o respeito e uma inclusão que toque no ponto central do reconhecimento - igual valor dos diferentes grupos - esta política pública

${ }^{40}$ MATTOS, Patrícia. A sociologia política do reconhecimento: as contribuições de Charles Taylor, Axel Honneth e Nancy Fraser. São Paulo: Annablume, 2006. p. 129. 
pode tornar-se exclusiva e discriminatória, fazendo do reconhecimento um não reconhecimento ou reconhecimento errôneo.

\section{CONSIDERAÇÕES FINAIS}

Ao considerar a educação como um direito fundamental social e, com isso, afirmar que todos os brasileiros devem ter acesso a um ensino qualitativo, o Estado toma para si o dever de, por meio de políticas públicas, permitir - ao menos o primeiro contato de um grupo minoritário, em ambientes que antes não contavam com a sua presença.

Com a análise a partir da acessibilidade dos alunos com necessidades específicas às escolas da rede regular de ensino do Município de Vitória/ES, é possível perceber que esse é apenas o primeiro passo na ação estatal de inclusão destes alunos nas referidas escolas em cumprimento à determinação legal contida na Lei de Diretrizes e Bases da Educação Nacional (LDBN no 9.394/96).

Contudo, a partir da teoria tayloriana, pode-se compreender que o reconhecimento não é algo que se estabelece apenas por meio da inclusão de pessoas em determinado espaço. O reconhecimento, por sua vez, requer ações - para a sua efetivação - que vão além de uma mera política pública destinada a promover a inclusão de um grupo minoritário em determinado local.

Em suma, para que haja o devido reconhecimento, é preciso a reunião de um conjunto de fatores, que inclui o respeito - por parte da comunidade que já se encontra estabelecido - e a preservação das identidades. Tais fatores consistem, por exemplo, na necessidade do espaço escolar se tornar plural e democrático, no sentido de permitir o convívio igualitário entre seus alunos - que possuem ou não necessidades específicas - e quando preciso adequar-se às características individuais de cada aluno.

Assim, ao Estado cumpre o dever de execução das políticas públicas, o que requer a disponibilização de verbas para execução de projetos interescolares, bem como a devida capacitação dos profissionais ligados à educação. Entretanto, é imprescindível a construção de um ordenamento jurídico que permaneça atento às mudanças enfrentadas pela sociedade, em especial no que tange ao grupo em questão, a fim de que o tratamento desigual concedido às pessoas com necessidades 
específicas aproxime-se de uma igualdade não discriminatória.

\section{REFERÊNCIAS}

ASSOCIAÇÃO BRASILEIRA DE NORMAS TÉCNICAS. NBR no 9050:2004. Disponível em: <http://www.pessoacomdeficiencia.gov.br/app/sites/default/files/ arquivos/\%5Bfield_generico_imagens-filefield-description\%5D_24.pdf $>$. Acesso em: 06 jan. 2015.

APPIAH, K. Anthony. Identidade, Autenticidade, Sobrevivência: sociedades multiculturais e reprodução social. In: TAYLOR, Charles; et al. Multiculturalismo: examinando a política de reconhecimento. Tradução de Marta Machado. Lisboa: Piaget, 1998, p. 165-179.

BARRETTO, Vicente de Paulo. Reflexões sobre os direitos sociais. In.: SARLET, Ingo Wolfgang (Org.). Direitos fundamentais sociais: estudos de direito constitucional internacional comparado. Rio de Janeiro: Renovar, 2003. p. 107-134.

BRASIL. Constituição [da] República Federativa do Brasil. Disponível em: $<$ http://www.planalto.gov.br/ccivil_03/constituicao/ConstituicaoCompilado.htm>. Acesso em: 06 de jan. de 2015.

BRASIL. Decreto no 3.956, de 8 de outubro de 2001. Promulga a Convenção Interamericana para a Eliminação de Todas as Formas de Discriminação contra as Pessoas Portadoras de Deficiência. Disponível em: < http://www.planalto.gov.br/ ccivil_03/decreto/2001/d3956.htm >. Acesso em: 09 de jan. de 2015.

BRASIL. Lei $\mathrm{n}^{0}$ 9.394, de 20 de dezembro de 1996. Estabelece as diretrizes e bases da educação nacional. Disponível em: < http://portal.mec.gov.br/seesp/arquivos/ pdf/lei9394_ldbn1.pdf > . Acesso em: 09 de jan. de 2015.

BRASIL. Lei no 8.069, de 13 de julho de 1990. Dispõe sobre o Estatuto da Criança e do Adolescente e dá outras providências. Disponível em: < http://www.planalto. gov.br/ccivil_03/leis/18069.htm>. Acesso em: 09 de jan. de 2015.

BRASIL. Lei $\mathbf{n}^{0} \mathbf{7 . 8 5 3}$ de 1989. Dispõe sobre o apoio às pessoas portadoras de 
deficiência, sua integração social, sobre a Coordenadoria Nacional para Integração da Pessoa Portadora de Deficiência - Corde, institui a tutela jurisdicional de interesses coletivos ou difusos dessas pessoas, disciplina a atuação do Ministério Público, define crimes, e dá outras providências. Disponível em: < http://www.planalto.gov. br/ccivil_03/leis/L7853.htm>. Acesso em: 10 jan. de 2015.

BOBBIO, Norberto. A era dos direitos. Tradução de Carlos Nelson Coutinho. Rio de Janeiro: Campus, 1992.

GUENTHER, Zenita Cunha. O aluno bem-dotado na escola regular: celebrando a diversidade, incluindo as diferenças. Revista Escritos sobre Educação, Ibirité, v. 2, n.1, p.43-54, jan-jun. 2003.

GUIMARÃES, Arthur. Inclusão que funciona. Revista Nova Escola, São Paulo, n. 165, p.43-47, set. 2003.

HABERMAS, Jurgen. A Luta por reconhecimento no Estado Democrático de Direito. In: A INCLUSÃO do outro: estudos de teoria política. Trad. George Sperber e Paulo Astor Soethe. São Paulo: Edições Loyola, capítulo 8, p. 229-254.

LINHARES, Monica Teresa Mansur. Ensino jurídico: educação, currículo e diretrizes curriculares no curso de Direito. São Paulo: Iglu, 2010.

MATTOS, Patrícia. A sociologia política do reconhecimento: as contribuições de Charles Taylor, Axel Honneth e Nancy Fraser. São Paulo: Annablume, 2006.

ROCKEFELLER, Steven C. Comentário. In: TAYLOR, Charles; et al. Multiculturalismo: examinando a política de reconhecimento. Trad. Marta Machado. Lisboa: Piaget, 1998, p. 105.

TAVARES, André Ramos. Curso de direito constitucional. 7. ed. São Paulo: Saraiva, 2009.

TAYLOR, Charles. Argumentos filosóficos. Tradução de Adail Ubirajara Sobral. São Paulo: Loyola, 2000.

TAYLOR, Charles. Argumentos filosóficos. Tradução de Adail Ubirajara Sobral. São 
Paulo: Loyola, 1998.

Recebido em: 09/08/2017

Aceito em: 21/03/2018 